\title{
Exigências proteicas de bovinos de corte suplementados a pasto ${ }^{1}$
}

\author{
Maykel Franklin Lima Sales ${ }^{2}$, Mário Fonseca Paulino ${ }^{3}$, Sebastião de Campos Valadares \\ Filho $^{3}$, Mario Luiz Chizzotti ${ }^{2}$, Lívia Vieira de Barros ${ }^{4}$, Marlos Oliveira Porto ${ }^{2}$
}

\footnotetext{
1 Pesquisa parcialmente financiada pelo CNPq e pela FAPEMIG

2 Pós-graduação em Zootecnia - UFV, Viçosa, MG.

${ }^{3}$ Departamento de Zootecnia - UFV, Viçosa, MG.

${ }^{4}$ Graduação em Zootecnia - UFV, Viçosa, MG.
}

RESUMO - Objetivou-se determinar as exigências proteicas de bovinos anelorados, em pastagem com Brachiaria decumbens suplementada com concentrado. Foram utilizados 28 novilhos zebuínos não-castrados com média de 7 meses de idade e $180 \mathrm{~kg}$. Foram abatidos oitos animais-referência para determinação da composição corporal inicial. Os 20 animais restantes foram divididos em cinco lotes de quatro animais, em delineamento inteiramente ao acaso, de modo que cada lote recebeu um dos cinco planos nutricionais: mantença; mistura mineral; e suplementação nos níveis de 0,75; 1,50 e $2,25 \mathrm{~kg} /$ animal/dia. A meia-carcaça direita de todos os animais foi dissecada em músculo, gordura e ossos e todos os constituintes do corpo foram pesados para determinação do peso de corpo vazio e da composição corporal. De posse desses dados, procedeu-se ao cálculo das exigências líquidas para ganho de peso em diversas faixas de peso corporal dos animais. Os conteúdos de proteína retidos no corpo dos animais foram regredidos em função do ganho de peso de corpo vazio e da energia retida. As exigências de proteína metabolizável total de um animal de $350 \mathrm{~kg}$ e ganho diário de 1,0 kg, foram de 593,59 g/dia. Esse mesmo animal, consumindo 7,40 kg de MS/dia, necessita de dietas com 12,97\% de PB na MS total. A exigência líquida de proteína para ganho de peso de animais anelorados não-castrados em pastejo, com até $350 \mathrm{~kg}$ de peso corporal, reduzem conforme o peso corporal ou a energia retida aumentam e pode ser estimada a partir da equação: PR $(\mathrm{g} / \mathrm{dia})=-26,2946+247,4853 \times \mathrm{GPCVZ}-24,8436 \times \mathrm{ER}$.

Palavras-chave: exigências nutricionais, proteína, suplementação, zebuínos

\section{Protein requirements of pasture supplemented beef cattle}

\begin{abstract}
The objective of this trial was to determine the protein requirements of Zebu bovines on Brachiaria decumbens Stapf. pasture supplemented with concentrate. It was used 28 non-castrated Zebu steers at an average age of 7 months and $180 \mathrm{~kg}$ average weight. Eight baseline animals were slaughtered to determine the initial body composition. The 20 remaining animals were divided in five plots of four animals, in a completely randomized design so each group received one out of the five nutritional plans: maintenance; mineral mix; and supplementation at the levels of 0.75 ; 1.50 and $2.25 \mathrm{~kg} /$ animal/day. In all animals, the right half carcass was dissected in muscle, fat and bones and all the body components were weighed to determine the empty body weight and empty body composition. These data allowed the calculations of net requirements forweight gain in several ranges of the body weight of the animals. Contents of protein withheld in the bodies of the animals were regressed in function of empty body gain and withheld energy. The requirements of total metabolizable protein for an animal with $350 \mathrm{~kg}$ and average daily weight gain of $1.0 \mathrm{~kg}$, were $593.59 \mathrm{~g} / \mathrm{day}$. That same animal, consuming $7.40 \mathrm{~kg}$ of DM/day requires diets with $12.97 \%$ of CP in total DM. The net requirement of protein for weight gain of non-castrated grazing Zebu bulls with up to $350 \mathrm{~kg}$ of body weight decreases as the body weight or retained energy increases, and it can be estimated by the equation: PR (g/day) $=-26.2946+247.4853 \times$ GPCVZ $-24.8436 \times$ ER .
\end{abstract}

Key Words: nutrient requirements, protein, supplementation, zebu cattle

\section{Introdução}

Em sistemas de produção de gado de corte, os custos com alimentação podem representar de 70 a $90 \%$ dos custos operacionais totais, dependendo da fase de criação e do nível de produção desejado (Valadares Filho et al., 2005).
Desta forma, o pecuarista deve maximizar a utilização do pasto para aumentar a rentabilidade do sistema produtivo. Além disso, devido à utilização de valores otimizados para o atendimento das exigências, o conhecimento dos requisitos proteicos dos bovinos pode resultar em economia nos custos com formulação de dietas, reduzindo os custos com 
alimentação, principalmente com relação às fontes proteicas, de custo mais elevado.

As pesquisas sobre exigências nutricionais de bovinos em crescimento, no Brasil, iniciaram-se em 1980. Desde então, foram desenvolvidos diversos experimentos para determinar a composição corporal e as exigências nutricionais de bovinos, sobretudo em confinamento, sendo apenas uma pequena parcela desses trabalhos realizados com animais em pastagens.

O conhecimento das exigências nutricionais de bovinos em pastejo, notadamente em proteína, é imprescindível para a formulação de suplementos que aumentem o consumo de pasto, melhorando o aproveitamento dos nutrientes potencialmente disponíveis e fazendo com que a dieta total consumida atenda às necessidades dos animais, melhorando seu desempenho, sem dispêndio de nutrientes.

Uma das principais metas da pesquisa para produção de carne é aumentar a deposição de proteína muscular e a eficiência de utilização dos aminoácidos da dieta. Para que a eficiência de síntese de proteína microbiana seja máxima, devem-se atender às necessidades dos microrganismos. E para maximizar a eficiência de utilização da proteína nos tecidos, a proteína microbiana e a proteína não-degradável no rúmen devem atender às exigências para síntese de tecidos, em termos quantitativos e qualitativos (Waldo \& Glen, 1981).

A demanda de proteína metabolizável para mantença (PMm) de um bovino é igual às perdas metabólicas fecais e urinárias, além daquelas perdas por descamação. O NRC (2000) recomenda 3,8 g/kg PV 0,75 como valor diário de exigência de proteína metabolizável para mantença. Já a AFRC (1993) sugere o valor de 2,3g g/kgPV ${ }^{0,75}$. No entanto, segundo Valadares Filho et al. (2006a), os valores observados em trabalhos realizados no Brasil são bastante variáveis e diferentes do sugerido pelo NRC (2000).

Objetivou-se determinar as exigências proteicas de bovinos anelorados em pastagem com Brachiaria decumbens suplementada com concentrado.

\section{Material e Métodos}

O experimento foi conduzido entre os dias 4/7/2005 e 6/4/2006 utilizando 28 novilhos anelorados, não-castrados, com 7 meses de idade e $180 \mathrm{~kg} \pm 48,09 \mathrm{~kg}$. Os abates dos animais foi dividido em quatro etapas.

Após o início do experimento, no dia 14/7/2005, na estação seca, foram abatidos dois animais, aos 7 meses e $180 \mathrm{~kg}$. No segundo abate, realizado no dia 10/10/2005, no início da fase de transição seca-águas, foram abatidos três animais com peso médio de $180 \mathrm{~kg}$, devido à presença de um animal muito leve (com $145 \mathrm{~kg}$ e 8 meses de idade esse animal deveria ser descartado). Os outros dois animais encontravam-se com 205 e $180 \mathrm{~kg}$ e 09 meses de idade.

No terceiro abate, realizado no dia 10/1/2006, no período das águas, foram abatidos outros três animais, aos 15 meses de idade e $305 \mathrm{~kg}$. Durante os abates, todos os constituintes do corpo (órgãos, vísceras, sangue, couro, cabeça e membros) foram pesados e amostrados para determinação do peso de corpo vazio e da composição corporal dos animais, em diferentes faixas de peso.

Os dados obtidos no terceiro abate foram utilizados para a estimativa da composição corporal inicial dos 20 animais mantidos no experimento. Os 20 animais restantes apresentavam idade média de 14 meses e $316 \mathrm{~kg} \pm 59,74 \mathrm{~kg}$ Foram divididos em cinco lotes de quatro animais, seguindo um delineamento inteiramente casualizado, de modo que cada lote recebeu um dos cinco planos nutricionais: mantença; mistura mineral; e suplemento $(0,75 ; 1,50$ ou 2,25 kg/animal/dia) contendo 33\% de proteína bruta (Tabelas 1 e 2). A mistura mineral foi fornecida à vontade a todos os animais.

Os quatro animais mantidos em nível de mantença foram manejados de forma a manter um nível mínimo de perda ou ganho de peso. Esses animais foram conduzidos ao pastejo por um período não superior a 4 horas e, em seguida, foram presos em uma área cercada ( 0,4 ha), isenta de forragem e com acesso apenas à água.

Tabela 1 - Composição do suplemento e do pasto

\begin{tabular}{lc}
\hline Ingrediente & $\begin{array}{c}\text { \% no suplemento } \\
\text { (\% matéria natural) }\end{array}$ \\
\hline Ureia/sulfato de amônia (9:1) & 2,50 \\
Milho & 31,00 \\
Farelo de soja & 16,50 \\
Farelo de algodão & 25,00 \\
Farelo de trigo & 25,00 \\
\hline
\end{tabular}

Tabela 2 - Composição do suplemento e do pasto

\begin{tabular}{lcc}
\hline & Suplemento & $\begin{array}{c}\text { B. decumbens } \\
\text { (extrusa esofágica) }\end{array}$ \\
\hline Matéria seca (\%) & 85,75 & 87,95 \\
Matéria orgânica (\% MS) & 95,42 & 90,35 \\
Proteína bruta (\% MS) & 33,62 & 10,84 \\
Fibra em detergente neutro (\% MS) & 23,93 & 61,79 \\
Extrato etéreo (\% MS) & 2,78 & 1,07 \\
Cinzas (\% MS) & 4,58 & 9,65 \\
Carboidratos não-fibrosos (\% MS) & 35,09 & 16,65 \\
Carboidratos totais (\% MS) & 59,01 & 78,45 \\
Lignina (\% MS) & 2,82 & 2,94 \\
Nitrogênio insolúvel em detergente & 1,75 & 28,27 \\
ácido (\% N total) & & \\
Nitrogênio insolúvel em detergente & 8,04 & 46,68 \\
neutro (\% N total) & & \\
\hline
\end{tabular}

R. Bras. Zootec., v.39, n.9, p.2066-2072, 2010 
A área experimental destinada aos animais foi constituída de cinco piquetes de 2,0 ha cada, formados com Brachiaria decumbens Stapf., providos de bebedouros e comedouros cobertos. Visando reduzir a influência da possível variação na disponibilidade de matéria seca de pasto, os animais permaneceram em cada piquete por sete dias e, posteriormente, procedeu-se ao rodízio entre os piquetes.

Por um período de dez dias, todos os animais foram submetidos a um ensaio de digestão a pasto, sendo os sete primeiros dias destinados à adaptação dos animais e à estabilização do fluxo dos indicadores conforme descrito por Titgemeyer et al. (2001).

Para avaliar a composição bromatológica da forragem consumida pelos animais, foram utilizados cinco animais fistulados no esôfago, os quais após jejum alimentar e hídrico de 16 horas foram conduzidos aos piquetes experimentais para a realização das coletas de extrusa. As coletas foram realizadas às $7 \mathrm{~h}$ da manhã do quinto dia do ensaio de digestão, utilizando-se bolsas coletoras com fundo telado, adaptadas em torno da fístula esofágica. Após 40 minutos de pastejo, as bolsas eram retiradas, e as amostras, pesadas.

Para estimar a excreção de matéria seca fecal (EF, kg/dia), segundo recomendações de Smith \& Reid (1955), utilizou-se o indicador externo óxido crômico, aplicado em dose única diária (10 g/animal), acondicionado em cartucho de papel e introduzido por meio de um aplicador diretamente no esôfago dos animais durante nove dias consecutivos. Após sete dias de adaptação, foram coletadas amostras de fezes dos animais no oitavo (16 h), nono (12 h) e décimo ( 8 h) dias. O cálculo da excreção fecal foi realizado tendo como base a razão entre a quantidade de indicador fornecido e sua concentração nas fezes, segundo a equação:

$$
\mathrm{EF}=(\mathrm{CrFo} / \mathrm{CrFe}) \times 100
$$

em que: $\mathrm{CrFo}=$ quantidade de cromo fornecida (g); $\mathrm{CrFe}=$ concentração de cromo nas fezes (\%).

O consumo voluntário de matéria seca foi estimado pela relação entre a excreção fecal e a indigestibilidade da dieta, a partir do indicador interno a FDA indigestível (FDAi) obtida após 264 horas de incubação in situ (Casali et al., 2008), por meio da equação:

$\mathrm{CMS}=\{[(\mathrm{EF} \times \mathrm{FDAiFe})-\mathrm{FDAiS}] / \mathrm{FDAiFOR}\}+\mathrm{CMSS}$ em que: FDAiFe $=$ FDAi nas fezes $(\mathrm{kg} / \mathrm{kg}) ; \mathrm{FDAiS}=\mathrm{FDAi}$ no suplemento (kg/dia); FDAiFOR = concentração de FDAi na forragem $(\mathrm{kg} / \mathrm{kg})$; CMSS = consumo de MS de suplemento (kg/dia).

Para determinação do consumo individual de suplemento (CMSs), foi utilizado o dióxido de titânio, 10 g/animal, misturado ao suplemento imediatamente antes do fornecimento, segundo procedimento descrito por Valadares Filho et al. (2006b), seguindo o mesmo esquema de coletas de fezes descrito para o oxido crômico, por meio da equação:

$$
\text { CMSs }=\left(\mathrm{EF} \times \mathrm{TiO}_{2} \mathrm{Fe}\right) / \mathrm{TiO}_{2} \mathrm{~S}
$$

em que: $\mathrm{TiO}_{2} \mathrm{Fe}$ e $\mathrm{TiO}_{2} \mathrm{~S}$ referem-se, respectivamente, à concentração de dióxido de titânio nas fezes e no suplemento.

Após a coleta, as amostras de extrusa e fezes foram secas em estufa com ventilação forçada, a $65^{\circ} \mathrm{C}$ por 72 horas, processadas em moinho tipo Willey com peneira de 1,0 mm e, posteriormente, submetidas às análises laboratoriais (Tabela 1), de acordo com as técnicas descritas por Silva \& Queiroz (2002), com exceção das determinações de FDN e FDA, que seguiram os métodos descritos por Mertens (2002) e Van Soest \& Robertson (1985).

A partir dos consumos de matéria seca, das excreções fecais e dos teores de nutrientes digestíveis totais das dietas, foi possível calcular a digestibilidade dos nutrientes e estimar os consumos de energia metabolizável.

O último abate foi realizado nos dias 27/3/2006, 29/3/2006, 3/4/2006 e 5/4/2006 de forma escalonada, após $76,78,83$ e 85 dias, sendo abatidos cinco animais por vez, um de cada tratamento. No momento do abate, os animais estavam com média de 17 meses de idade e $378 \mathrm{~kg}(\mathrm{~s}=57,62)$. Antes do abate, todos os animais foram submetidos a um jejum de 16 horas para obtenção do peso corporal em jejum. Após o abate, o trato gastrintestinal de cada animal foi pesado, esvaziado e lavado, sendo seu peso somado ao dos órgãos e demais partes do corpo (carcaça, cabeça, couro, cauda, pés e sangue) para determinação do peso de corpo vazio (PCVZ). A relação entre o peso de corpo vazio (PCVZ) e o peso corporal dos animais, em cada abate, foi utilizada para estimativa do peso de corpo vazio dos animais mantidos no experimento. Dentro de cada tratamento, foram sorteados dois animais para representá-lo, dos quais se retiraram amostras da cabeça e de um membro anterior e outro posterior, para separação física de tecido mole, ossos e couro.

As amostras de sangue foram coletadas imediatamente após a secção da veia jugular dos animais, acondicionadas em recipiente de vidro e deixadas em estufa com ventilação forçada a $55^{\circ} \mathrm{C}$ por 72 horas. As amostras de carne industrial, fígado, coração, rins, baço, pulmões, língua, rúmen, retículo, omaso, abomaso, intestino delgado, intestino grosso, mesentério, gordura interna, aparas e cauda foram agrupadas, processadas e homogeneizadas integralmente em um Cutter de 65 litros, de onde foi retirada uma amostra que representou os órgãos e as vísceras.

A carcaça de cada animal foi dividida em duas metades e, em seguida, foram pesadas e resfriadas em câmara fria a 
$-2,5^{\circ} \mathrm{C}$ por aproximadamente 18 horas. Decorrido esse tempo, as carcaças direitas de dez animais, dois por tratamento, foram retiradas da câmara fria e totalmente dissecadas, procedendo-se à separação em músculos, gordura e ossos, que foram posteriormente pesados. A composição corporal dos outros dez animais foi estimada por meio dos percentuais de músculo, gordura e ossos das carcaças dissecadas.

Os tecidos muscular e adiposo foram moídos, e o tecido ósseo serrado em pequenos cubos. Foi retirada uma amostra representativa de cada componente, para determinação direta dos teores de proteína e gordura da carcaça.

Após a moagem, as amostras frescas foram acondicionadas em recipientes de vidro e secas em estufa a $105^{\circ} \mathrm{C}$ por 48 horas para obtenção da matéria seca gordurosa (MSG), e, posteriormente, lavadas seguidamente com éter etílico para obtenção da matéria seca pré-desengordurada (MPSD), conforme procedimento descrito por Paulino et al. (2004). Em seguida, as amostras pré-desengorduradas foram moídas em moinho tipo bola, para posteriores quantificações dos teores de nitrogênio total e extrato etéreo, conforme recomendações de Silva \& Queiroz (2002). O teor de proteína foi obtido pelo produto do teor de nitrogênio total e o fator 5,88 conforme sugerido por Baldwin (1995). O teor de energia foi calculado utilizando os valores calóricos de 9,3929 e 5,6405 Mcal/kg (ARC, 1980), para gordura e proteína, respectivamente.

O conteúdo de proteína no corpo vazio foi determinado em função da concentração percentual nas amostras dos constituintes separados da carcaça e nas amostras de órgãos e vísceras, couro, sangue, cabeça e membros.

Em todas as análises estatísticas foi utilizado o procedimento GLM do programa SAS 9.1, adotando-se valor P inferior a 0,05 para avaliar a significância dos parâmetros.

Os conteúdos de proteína retidos no corpo dos animais foram estimados por meio da regressão linear do logaritmo do conteúdo corporal de proteína no logaritmo do PCVZ, segundo o ARC (1980), conforme o seguinte modelo:

$$
\mathrm{Y}=\mathrm{a}+\mathrm{bX}+\mathrm{e}
$$

em que: $\mathrm{Y}=$ logaritmo do conteúdo total de proteína $(\mathrm{kg})$ retido no corpo vazio; $\mathrm{a}=$ intercepto; $\mathrm{b}=$ coeficiente de regressão; $\mathrm{X}=$ logaritmo do peso de corpo vazio; e = erro aleatório.

As equações foram elaboradas adicionando-se os valores relativos aos animais referência, sendo dois animaisreferência do primeiro abate, três do segundo e três do terceiro, além dos 20 animais do abate final.

Derivando-se as equações de predição do conteúdo corporal de proteína em função do logaritmo do peso de corpo vazio, obtiveram-se as exigências líquidas de proteína, por kg de ganho de ganho de peso de corpo vazio (GPCVZ), a partir da equação (ARC, 1980):

$$
\mathrm{Y}^{\prime}=\text { b. } 10^{\mathrm{a}} \cdot \mathrm{X}^{\mathrm{b}-1}
$$

em que: $\mathrm{Y}^{\prime}=$ conteúdo de proteína no ganho $(\mathrm{g} / \mathrm{kg}$ de GPCVZ), ou exigências líquidas de proteína para ganho; a e b = intercepto e coeficiente de regressão da equação de predição do conteúdo corporal de proteína; $\mathrm{X}$ = peso de corpo vazio (kg).

As exigências de proteína líquida para ganho foram obtidas pela regressão linear múltipla da proteína retida (PR, g/dia) no GPCVZ (kg/dia) e na energia retida (ER, Mcal/ dia) de acordo com a equação:

\section{$\mathrm{PR}=\mathrm{c}+\mathrm{d} \times \mathrm{GPCVZ}+\mathrm{e} \times \mathrm{ER}+\mathrm{e}$}

Os requisitos de proteína metabolizável para mantença e ganho e as exigências de proteína bruta foram obtidos segundo as recomendações do NRC (2000).

\section{Resultados e Discussão}

A relação obtida para a estimativa do peso de corpo vazio (PCVZ) a partir do peso corporal (PC) dos animais foi: $P C V Z=P C \times 0,8997$, valor próximo àqueles recomendados pelo NRC (2000), de 0,891, e por Valadares Filho et al. (2006a), de 0,8960.

Para conversão das exigências para ganho de peso de corpo vazio (GPCVZ) em exigências para ganho de peso corporal (GPC), deve-se utilizar a relação: GPCVZ = $0,93 \times$ GPC, praticamente igual àquela recomendada por Valadares Filho et al. (2006a), que foi de 0,933.

A equação de regressão do logaritmo do conteúdo de proteína no corpo vazio no logaritmo do PCVZ obtida neste experimento foi:

$\log$ PB $(k g)=-0,6858+0,9838 \times \log$ PCVZ $\left(r^{2}=0,99\right)$

As exigências de proteína no ganho de peso de corpo vazio decresceram à medida que o peso corporal dos animais elevou (Tabela 3). Essa tendência está de acordo com as observações de Fregadolli (2005) e Moraes et al. (2010) em animais em pastejo e está relacionada à diminuição da deposição de proteína à medida que o peso do animal aproxima-se do seu peso à maturidade.

Tabela 3 - Exigências líquidas de proteína de zebuínos de acordo com o peso corporal

\begin{tabular}{cc}
\hline Peso corporal $(\mathrm{kg})$ & Exigência de proteína (g/kg GPCVZ) \\
\hline 150 & 187,33 \\
200 & 186,45 \\
250 & 185,78 \\
300 & 185,23 \\
350 & 184,77 \\
\hline
\end{tabular}

$\mathrm{PCVZ}=\mathrm{PV} \times 0,8997 ; \mathrm{GPCVZ}-$ ganho de peso de corpo vazio 
Fregadolli (2005), em pesquisa com novilhos Nelore com peso corporal inicial de $293 \mathrm{~kg}$ e final de $450 \mathrm{~kg}$, encontrou exigências líquidas de proteína para ganho de peso variando de 156 a $145 \mathrm{~g} / \mathrm{kg}$ de ganho de peso de corpo vazio, com o peso dos animais variando de 250 a $350 \mathrm{~kg}$ de peso corporal. Moraes et al. (2010), no entanto, trabalhando com novilhos anelorados com peso corporal inicial de $311 \mathrm{~kg}$ em pastejo, relataram exigências de 153,72 e 145,13 g/kg de ganho de peso de corpo vazio com 250 e $350 \mathrm{~kg}$ de peso corporal.

A partir desses dados, observa-se que, embora seguindo a tendência de redução das exigências líquidas de proteína com o aumento do peso corporal, os resultados foram numericamente superiores aos reportados na literatura para a mesma faixa de peso.

Esse comportamento das exigências líquidas de proteína para ganho pode ser explicado pelas modificações na curva de crescimento de animais mantidos em pastejo, em relação àqueles confinados. Segundo Owens (1993), a curva de crescimento dos bovinos pode ser representada por uma sigmoide com duas fases distintas, que se caracterizam por tendências bastante diferentes. Na primeira fase, o crescimento é acelerado, em razão do desenvolvimento dos tecidos ósseo e muscular, ativado pela liberação dos hormônios tiroxina e somatotropina, ocorrendo maior síntese de tecido muscular em relação ao adiposo. Isso poderia explicar a maior exigência proteica encontrada no presente experimento, indicando que os animais ainda não haviam alcançado o peso associado à segunda fase de sua curva de crescimento, visto que a redução na taxa de deposição de proteína, em bovinos, está associada a aumentos no desenvolvimento do tecido adiposo à medida que o animal aproxima-se de seu peso adulto (peso à maturidade), que resultam em acréscimos nas exigências de energia para ganho de peso com o aumento do peso corporal dos animais.

Devido à interação entre a deposição de gordura e proteína, foi realizada a regressão múltipla da proteína retida (PR, kg/dia), em função da energia retida (ER, Mcal/ dia) e do ganho de peso de corpo vazio (GPCVZ, kg/dia), para estimar as exigências líquidas de proteína para qualquer faixa de peso e ganho de peso (Tabela 4):

$\mathrm{PR}(\mathrm{g} / \mathrm{dia})=-26,2946+247,4853 \times \mathrm{GPCVZ}-24,8436 \times$ $\operatorname{ER}\left(R^{2}=0,93\right)$

A partir dessa equação, tomando-se como referência um animal com $350 \mathrm{~kg}$ de peso corporal com ganho médio diário de 0,50 kg/dia e empregando-se a nergia retida de 1,29 Mcal/dia (Tabela 6), obtém-se o valor de proteína retida ou de exigências líquidas de proteína para ganho de peso de 56,76 g/dia (Tabela 4).
Tabela 4 - Exigências líquidas de proteína para ganho de peso (g/dia) de zebuínos de cinco classes de peso e taxas de ganho de peso

\begin{tabular}{cccccc}
\hline $\begin{array}{c}\text { Ganho de peso } \\
\text { (kg/dia) }\end{array}$ & \multicolumn{5}{c}{ Peso corporal $(\mathrm{kg})$} \\
\cline { 2 - 6 } & 150 & 200 & 250 & 300 & 350 \\
\hline 0,50 & 71,82 & 67,74 & 63,90 & 60,25 & 56,76 \\
0,75 & 119,28 & 112,77 & 106,66 & 100,85 & 95,27 \\
1,00 & 166,22 & 157,16 & 148,65 & 140,56 & 132,80 \\
\hline
\end{tabular}

Aplicando a equação descrita por Moraes et al. (2010) para bovinos anelorados em pastejo, PR (g/dia) $=-34,6109$ $+257,956 \times \mathrm{GPVJ}-17,01 \times \mathrm{ER}\left(\mathrm{R}^{2}=0,69\right)$, adotando-se $\mathrm{ER}=1,97 \mathrm{Mcal} / \mathrm{dia}$ (obtida pelos autores), temos o valor de proteína retida estimado em $60,86 \mathrm{~g} / \mathrm{dia}, 7,2 \%$ superior ao obtido neste estudo.

Adicionalmente, se empregarmos a equação descrita por Chizzotti et al. (2008), para novilhos mestiços Nelore $\times$ Bos taurus, em um trabalho de meta-análise realizado com dados nacionais $(\mathrm{PR}=-17,3+233 \times \mathrm{GPCVZ}-18,7 \mathrm{ER})$, utilizando a $\mathrm{ER}=1,69 \mathrm{Mcal} /$ dia (obtida pelos autores) chegamos ao valor de $\mathrm{PR}=59,44 \mathrm{~g} /$ dia, cerca de 4,5\% superior ao encontrado no presente trabalho.

Adotou-se o valor de $4,00 \mathrm{~g} / \mathrm{kg} \mathrm{PV}^{0,75}$ para se obter as exigências de proteína metabolizável para mantença (PMm) de bovinos Nelore (Tabela 5), proposto pelo BR-Corte (Valadares Filho et al., 2006a).

Para os requisitos de proteína metabolizável para ganho (PMg), adotaram-se as eficiências de utilização da $\mathrm{PMg}$ recomendadas pelo NRC (2000). Para animais com peso de corpo vazio acima de $300 \mathrm{~kg}$, foi utilizada uma eficiência de utilização constante de 49,2\%. Para os animais com peso de corpo vazio inferior ou igual a $300 \mathrm{~kg}$, utilizou-se a seguinte equação para o cálculo da eficiência da proteína metabolizável para ganho: Eficiência $=[83,4-(0,114 \times$ PCVZ)].

As exigências totais de proteína metabolizável para um animal de $350 \mathrm{~kg}$ e ganho diário de 1,0 kg, foram de

Tabela 5 - Exigências de proteína metabolizável para mantença, ganho de peso e exigências totais de zebuínos, em função do peso corporal

\begin{tabular}{cccc}
\hline Peso corporal $(\mathrm{kg})$ & $\mathrm{PMm}^{1}$ & $\mathrm{PMg}^{2}$ & $\mathrm{PMt}$ \\
\hline 150 & 171,45 & 244,39 & 415,84 \\
200 & 212,73 & 249,90 & 462,64 \\
250 & 251,49 & 257,36 & 508,85 \\
300 & 288,34 & 267,06 & 555,40 \\
350 & 323,68 & 269,91 & 593,59 \\
\hline
\end{tabular}

$14,0 \mathrm{~g} / \mathrm{kg} \mathrm{PV}^{0,75}$

2 Exigência líquida/0,492 para PCVZ > 300 kg e Exigência líquida/(83,4 $(0,114 \times$ PCVZ) $)$ para PCVZ $\leq 300 \mathrm{~kg}$.

${ }^{3} \mathrm{PMt}=\mathrm{PMm}+\mathrm{PMg}$. 
593,59 g/dia (Tabela 5). Em trabalho com animais anelorados, sob pastejo, Moraes et al. (2010) determinaram as exigências totais de proteína metabolizável de um novilho de $350 \mathrm{~kg}$ em 618,48 g/dia, valor $4 \%$ superior ao encontrado no presente trabalho. No entanto, o valor encontrado foi cerca de 12,8\% inferior ao apresentado pelo BR-Corte (Valadares Filho et al., 2006a), que sugerem para o mesmo animal ( $350 \mathrm{~kg}$ e ganho de $1,0 \mathrm{~kg} /$ dia) exigências totais de proteína metabolizável de 680,76 g/dia.

A partir das exigências de proteína metabolizável (Tabela 5) e seguindo as recomendações do NRC (2000) para conversão dos requisitos totais de proteína metabolizável em exigências de proteína bruta (PB), foram calculados os requisitos diários totais de $\mathrm{PB}$ e as exigências de proteína degradada e não-degradada no rúmen (Tabela 6) para mantença e ganho de peso.

De forma geral, à medida que o animal cresce, as exigências de proteína não-degradável no rúmen decrescem, o que, segundo Silva et al. (2002), possibilita maior participação da proteína degradável no rúmen no suprimento das exigências totais de proteína bruta, indicando que para animais em fase de terminação maiores níveis de nitrogênio não proteico podem ser utilizados na dieta.

Para determinação do consumo de matéria seca (CMS) dos animais, em determinado peso corporal e faixa de ganho de peso, foi gerada a seguinte equação, a partir dos dados experimentais:

CMS $=-1,80+0,0113 \mathrm{PV}+6,40 \mathrm{GMD}-1,15 \mathrm{GMD}^{2}$ $\left(\mathrm{R}^{2}=0,83\right)$

Com base nessa equação e tomando-se como exemplo um animal com $350 \mathrm{~kg}$ de peso corporal, ganhando 1,0 kg/dia, temos um consumo de matéria seca de 7,40 kg/dia. Portanto, para um animal de $350 \mathrm{~kg}$ de peso corporal ganhar 1,0 kg/dia, mantido em condições de pastejo, é necessário que a dieta total apresente $12,97 \%$ de proteína bruta na matéria seca.

Tabela 6 - Consumo médio de nutrientes digestíveis totais e exigências de proteína de zebuínos sob pastejo, em função do peso corporal

\begin{tabular}{ccccc}
\hline $\begin{array}{c}\text { Peso corporal } \\
(\mathrm{kg})\end{array}$ & $\begin{array}{c}\mathrm{NDT}^{1} \\
(\mathrm{~kg} / \mathrm{dia})\end{array}$ & $\begin{array}{c}\mathrm{PDR}^{2} \\
\text { (g/dia) }\end{array}$ & $\begin{array}{c}\mathrm{PNDR}^{3} \\
\text { (g/dia) }\end{array}$ & $\begin{array}{c}\mathrm{PB}^{4} \\
\text { (g/dia) }\end{array}$ \\
\hline 150 & 3,10 & 412,92 & 222,19 & 635,11 \\
200 & 3,84 & 511,49 & 209,65 & 721,14 \\
250 & 4,54 & 604,73 & 200,22 & 804,95 \\
300 & 5,21 & 693,97 & 194,09 & 888,06 \\
350 & 5,85 & 779,22 & 180,38 & 959,60 \\
\hline
\end{tabular}

${ }^{1} \mathrm{NDT}=\mathrm{EM} / 0,82 / 4,409$.

$2 \mathrm{PDR}=120(\mathrm{~g} / \mathrm{kg}$ NDT $) \times 1,11$.

${ }^{3} \mathrm{PNDR}=(\mathrm{PMTotal}-(\mathrm{PDR} / 1,11 \times 0,64)) / 0,8$.

4 PDR + PNDR.

NDT - nutrientes digestíveis totais; PDR - proteína degradável no rúmen; PNDR - proteína não-degradável no rúmen; PB - proteína bruta.
Este resultado corrobora as observações de Bailey \& Duff (2005), de que as exigências de proteína bruta de bovinos de corte em fase de terminação se encontram entre 12,0 e $13,0 \%$.

Moraes et al. (2010) determinaram as exigências dietéticas de bovinos de corte terminados a pasto em 11,7 e 10,6\% de proteína bruta, para animais não-suplementados e suplementados, respectivamente. Da mesma forma, Moraes et al. (2010), trabalhando com animais em terminação a pasto encontrou ganho médio diário próximo de $1,0 \mathrm{~kg}$ quando a dieta apresentou 10,7\% de proteína bruta.

Tabela 7 - Exigências nutricionais de energia e proteína para ganho de peso de bovinos anelorados não-castrados de cinco classes de peso

\begin{tabular}{lllllll}
\hline & \multicolumn{5}{c}{ Peso corporal (kg) } \\
\cline { 2 - 6 } & 150 & 200 & 250 & 300 & 350 \\
\hline & \multicolumn{5}{c}{ Exigências de mantença } \\
$\begin{array}{l}\text { Energia líquida de mantença } \\
\text { (Mcal/dia) }^{1}\end{array}$ & 3,26 & 4,05 & 4,78 & 5,49 & 6,16 \\
Proteína metabolizável de & 171,45 & 212,73 & 251,49 & 288,34 & 323,68
\end{tabular}
mantença $(\mathrm{g} / \text { dia })^{2}$

Ganho de $0,50 \mathrm{~kg} / \mathrm{dia}$ Energia líquida para ganho (Mcal/dia) ${ }^{3}$

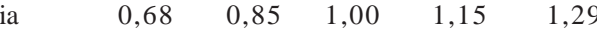
Ganho de $1,00 \mathrm{~kg} /$ dia $\quad 1,52 \quad 1,88 \quad 2,22 \quad 2,55 \quad 2,86$ Ganho de 0,50 kg/dia $\quad 105,60 \quad 107,71 \quad 110,63 \quad 114,49 \quad 115,36$ Ganho de 1,00 kg/dia $\quad 244,39 \quad 249,90 \quad 257,36 \quad 267,06 \quad 269,91$

Ganho de $0,50 \mathrm{~kg} / \mathrm{dia}$ Ganho de 1,00 kg/dia

Ganho de $0,50 \mathrm{~kg} / \mathrm{dia}$ Ganho de 1,00 kg/dia

Ganho de 0,50 kg/dia Ganho de $1,00 \mathrm{~kg} / \mathrm{dia}$

Exigências totais Energia metabolizável (Mcal/dia $)^{6}$ $\begin{array}{lllll}8,28 & 10,27 & 12,14 & 13,92 & 15,63\end{array}$ $11,14 \quad 13,82 \quad 16,34 \quad 18,74 \quad 21,03$

Nutrientes digestíveis totais $(\mathrm{kg} / \mathrm{dia})^{7}$ $2,30 \quad 2,85 \quad 3,37 \quad 3,86 \quad 4,34$ $3,10 \quad 3,84 \quad 4,54 \quad 5,21 \quad 5,85$

Proteína degradável no rúmen (g/dia) ${ }^{8}$ $306,36 \quad 379,62 \quad 448,88 \quad 514,15 \quad 578,09$ $412,92 \quad 511,49 \quad 604,73 \quad 693,97 \quad 779,22$

Proteína não-degradável no rúmen (g/dia) ${ }^{9}$

Ganho de 0,50 kg/dia Ganho de 1,00 kg/dia $125,50 \quad 126,95 \quad 129,13 \quad 132,97 \quad 132,16$ $222,19 \quad 209,65 \quad 200,22 \quad 194,09 \quad 180,38$

Proteína bruta $(\mathrm{g} / \mathrm{dia})^{10}$

Ganho de 0,50 kg/dia $\quad 431,86 \quad 506,57 \quad 578,02 \quad 647,12 \quad 710,24$ Ganho de $1,00 \mathrm{~kg} / \mathrm{dia}$ $635,11 \quad 721,14 \quad 804,95 \quad 888,06 \quad 959,60$

${ }^{1} \mathrm{ELm}=82,4 \mathrm{kcal} / \mathrm{PCVZ}^{0,75}$ (Sales et al., 2009).

$2 \mathrm{PMm}=4,0 \mathrm{~g} / \mathrm{kg} \mathrm{PV}^{0,75}$ (Valadares Filho et al., 2006a).

$3 \mathrm{ELg}=0,0416 \times \mathrm{PCVZ}^{0,75} \times \mathrm{GPCVZ}^{1,1499}$ (Sales et al., 2009).

${ }^{4} \mathrm{PR}(\mathrm{g} / \mathrm{dia})=-26,2946+247,4853 \times \mathrm{GPCVZ}-24,8436 \times \mathrm{ER}$.

$5 \mathrm{PM}=\mathrm{PR} / 0,492$ para PCVZ $>300 \mathrm{~kg}$ ou PR/[83,4-(0,114 $\times$ PCVZ) $]$ para PCVZ $\leq 300 \mathrm{~kg}$ (NRC, 2000).

${ }^{6} \mathrm{k}_{\mathrm{m}}=0,55 \mathrm{e} \mathrm{k}_{\mathrm{g}}=0,29$ (dieta com 2,33 Mcal $/ \mathrm{kg}$ de MS).

$7 \mathrm{NDT}=\mathrm{EM} / \mathrm{0}, 82 / 4,409$ (NRC, 2000).

8 PDR $=$ exigências NDT $(\mathrm{kg} / \mathrm{dia}) \times 120 \times 1,11$.

9 PNDR $=[$ PM total $-(\mathrm{PDR} / 1,11 \times 0,64)] / 0,8$.

${ }^{10} \mathrm{~PB}=\mathrm{PDR}+\mathrm{PNDR}$ 
Segundo Paulino et al. (2004), é importante o conhecimento do comportamento das exigências nutricionais dos animais de maneira conjunta, uma vez que energia e proteína estão intimamente associadas no metabolismo dos bovinos. Desta forma, é apresentado um resumo das exigências proteicas e energéticas de bovinos de corte sob pastejo, para diferentes pesos corporais e taxas de ganho de peso corporal (Tabela 7).

À medida que o peso corporal aumenta, as exigências líquidas de energia também aumentam, devido à maior deposição de gordura corporal, o que contribui diretamente para o aumento das exigências energéticas. Adicionalmente, as exigências de proteína diminuem, em virtude da queda no desenvolvimento muscular quando os animais se aproximam do peso à maturidade.

\section{Conclusões}

A exigência líquida de proteína para ganho de peso de animais anelorados não-castrados em pastejo diminui de acordo com o aumento do peso corporal ou da energia retida e pode ser estimada, para animais com até $350 \mathrm{~kg}$ de peso corporal, por meio da equação: PR (g/dia) $=-26,2946+$ $247,4853 \times$ GPCVZ $-24,8436 \times E R$.

\section{Referências}

AGRICULTURAL AND FOOD RESEARCH COUNCIL - AFRC. Energy and protein requirements of ruminants. Wallingford: 1993. 159p.

AGRICULTURAL RESEARCH COUNCIL - ARC. The nutrient requirements of ruminants livestock. London: Commonwealth Agricultural Bureaux, 1980. 351p.

BAILEY, C.R.; DUFF, G.C. Protein requirements of finishing beef cattle. In: SOUTHWEST NUTRITION CONFERENCE, 2005, Tempe. Proceedings... Tempe: University of Arizona, 2005. p.78-85.

BALDWIN, R.L. Modeling ruminant digestion and metabolism. London: Chapman and Hall, 1995. 592p.

CHIZZOTTI, M.L.; TEDESCHI, L.O.; VALADARES FILHO, S.C. A meta-analysis of energy and protein requirements for maintenance and growth of Nellore cattle. Journal of Animal Science, v.86, p.1588-1597, 2008.

FREGADOLLI, F.L. Composição corporal e exigências nutricionais de novilhos de três grupos genéticos em pastejo. 2005. 85f. Tese (Doutorado em Zootecnia) Universidade Estadual Paulista, Faculdade de Ciências Agrárias e Veterinárias, Jaboticabal.
MERTENS, D.R. Gravimetric determination of amylase treated neutral detergent fiber in feeds with refluxing in beakers or crucibles: Collaborative study. Journal of AOAC International, v.85, n.6, p.1212-1240, 2002.

MORAES, E.H.B.K.; PAULINO, M.F.; MORAES, K.A.K. et al. Exigências de proteína de bovinos anelorados em pastejo. Revista Brasileira de Zootecnia, v.39, n.3, p.601-607, 2010.

NATIONAL RESEARCH COUNCIL - NRC. Nutrient requirements of beef cattle. 7. rev. ed. Washington, D.C.: National Academic Press, 2000. 242p.

OWENS, F.N.; DUBESK, P.; HANSON, C.F. Factors that alter the growth and development of ruminants. Journal of Animal Science, v.71, p.3138-3150, 1993.

PAULINO, P.V.R; COSTA, M.A.L.; VALADARES FILHO, S.C. et al. Exigências nutricionais de zebuínos. Proteína. Revista Brasileira de Zootecnia, v.33, n.3, p.759-769, 2004.

SALES, M.F.L.; PAULINO, M.F.P.; VALADARES FILHO, S.C. et al. Composição corporal e requisitos energéticos de bovinos de corte sob suplementação em pastejo. Revista Brasileira de Zootecnia, v.38, n.7, p.1355-1362, 2009.

SILVA, D.J; QUEIROZ, A.C. Análise de alimentos (métodos químicos e biológicos). 3.ed. Viçosa, MG: Universidade Federal de Viçosa, 2002. 235p.

SILVA, F.F.; VALADARES FILHO, S.C.; ÍTAVO, L.C.V. et al. Composição corporal e requisitos energéticos e proteicos de bovinos nelore, não castrados, alimentados com rações contendo diferentes níveis de concentrado e proteína. Revista Brasileira de Zootecnia, v.31, n.1, p.503-513, 2002.

SMITH, A.M.; REID, J.T. Use of chromic oxide as an indicator of fecal output for the purpose of determining the intake of a pasture herbage by grazing cows. Journal of Dairy Science, v.38, n.5, p.515-524, 1955.

TITGEMEYER; E.C.; ARMENDARIZ, C.K.; BINDEL, D.J. et al. Evaluation of titanium dioxide as a digestibility marker for cattle. Journal of Animal Science, v.79, p.1059-1063, 2001.

VALADARES FILHO, S.C.; PAULINO, P.V.R.; VALADARES, R.F.D. et al. Exigências nutricionais de Zebuínos no Brasil. I. Proteína. In: VALADARES FILHO, S.C.; PAULINO, P.V.R.; MAGALHÃES, K.A. (Orgs.). Exigências Nutricionais de Zebuínos e Tabelas de Composição de Alimentos. BRCorte. 1.ed. Visconde do Rio Branco: Suprema Gráfica Ltda., 2006a. p.75-84.

VALADARES FILHO, S.C.; MORAES, E.H.B.K.; DETMANN, E. et al. Perspectivas do uso de indicadores para estimar o consumo individual de bovinos alimentados em grupo. In: REUNIÃO ANUAL DA SOCIEDADE BRASILEIRA DE ZOOTECNIA, 43. 2006, João Pessoa. Anais... João Pessoa: SBZ, UFPB, 2006b. p.291-322.

VALADARES FILHO, S.C.; PAULINO, P.V.R.; SAINZ, R.D Desafios metodológicos para determinação das exigências nutricionais de bovinos de corte no Brasil. In: REUNIÃO ANUAL DA SOCIEDADE BRASILEIRA DE ZOOTECNIA, 42., 2005, Goiânia. Anais... Goiânia: SBZ, 2005. p.261-287.

VAN SOEST, P.J.; ROBERTSON, J.B. Analysis of forages and fibrous foods. Ithaca: Cornell University, 1985. 202p.

WALDO, D.R.; GLEN, B.P. Foreign systems for meeting the protein requirements of ruminants. II. Meeting protein requirements of cattle. In: OWENS, F.N. (Ed). Proceedings... Stillwater, Oklahoma. Protein requirements for cattle: Symposium, 1981. p.269-309. 